\title{
EDITORIAL
}

\section{POSTDIGITAL RESEARCH}

\section{Christian Ulrik Andersen, Geoff Cox, Georgios Papadopoulos}

APRJA Volume 3, Issue 1, 2014

ISSN 2245-7755

CC license: 'Attribution-NonCommercial-ShareAlike'. 
'Post-digital Research' is the outcome of an extensive peer process. In August 2013 a number of researchers responded to an open call to participate in a research/Ph.D workshop organized by Aarhus University and transmediale, Berlin. In advance of meeting, each participant prepared a short text addressing the notion of the post-digital, posted it online and commented upon each others' contributions (postdigital.projects. cavi.dk). The group then met at Kunsthal Aarhus in October, where they - in an ongoing peer-review process - presented, critiqued and further developed their writings. This included the invention of a common working definition of the post-digital:

\begin{abstract}
Post-digital, once understood as a critical reflection of "digital" aesthetic immaterialism, now describes the messy and paradoxical condition of art and media after digital technology revolutions. "Post-digital" neither recognizes the distinction between "old" and "new" media, nor ideological affirmation of the one or the other. It merges "old" and "new", often applying network cultural experimentation to analog technologies which it reinvestigates and re-uses. It tends to focus on the experiential rather than the conceptual. It looks for DIY agency outside totalitarian innovation ideology, and for networking off big data capitalism. At the same time, it already has become commercialized.
\end{abstract}

Following this, the current issue of $A$ Peer-reviewed Newspaper (Volume 3 Issue 1 ), and the current issue of $A$ Peer-reviewed Journal About Post-digital Research (Volume 3 issue 1) have been developed. The peerreviewed newspaper was developed as a 'sprint', where the group decided to rewrite their contributions using a set of constraints.
Building on shared impressions of the postdigital, a common vocabulary was developed that included a list of words considered good to use in their writings (those words that were shared), alongside a list of those that were considered taboo (words that only had a single instance). Over the course of two days, all articles were rewritten and made more concise, and in addition a script was developed to analyse how each text compared to the common working definition of the post-digital (written by Florian Cramer). Another script (written by James Charlton) analysed all submitted images and compared them to the average of all images (displayed overleaf).

Whereas the newspaper reflects the post-digital in relation to the changing conditions of research in 'the afterglow' of a digital revolution (related to the thematic framework of transmediale 2014, entitled "Afterglow"), the peer-reviewed journal further reflects the developed arguments of the participants' research in a lengthier academic format.

Although in many ways the post-digital "sucks but is useful" as Florian Cramer notes in his article, the journal takes it to be a serious concept that deserves our critical attention. The journal issue is divided into three sections, that address the term itself, its genealogy and wider connotations, as well as its potential usefulness across different fields (including art, acoustics, aesthetic theory, political economy and philosophy). Given that the term comes from practice, it also addresses how the post-digital potentially operates as a framework for practice-based research that relate to material and historical conditions. As part of this, the journal includes a commissioned artwork, Psychoacademic dérive by Christophe Bruno, to make comment on the political economy of academic citation.

Aarhus, February 2014

Overleaf: All images combined. 


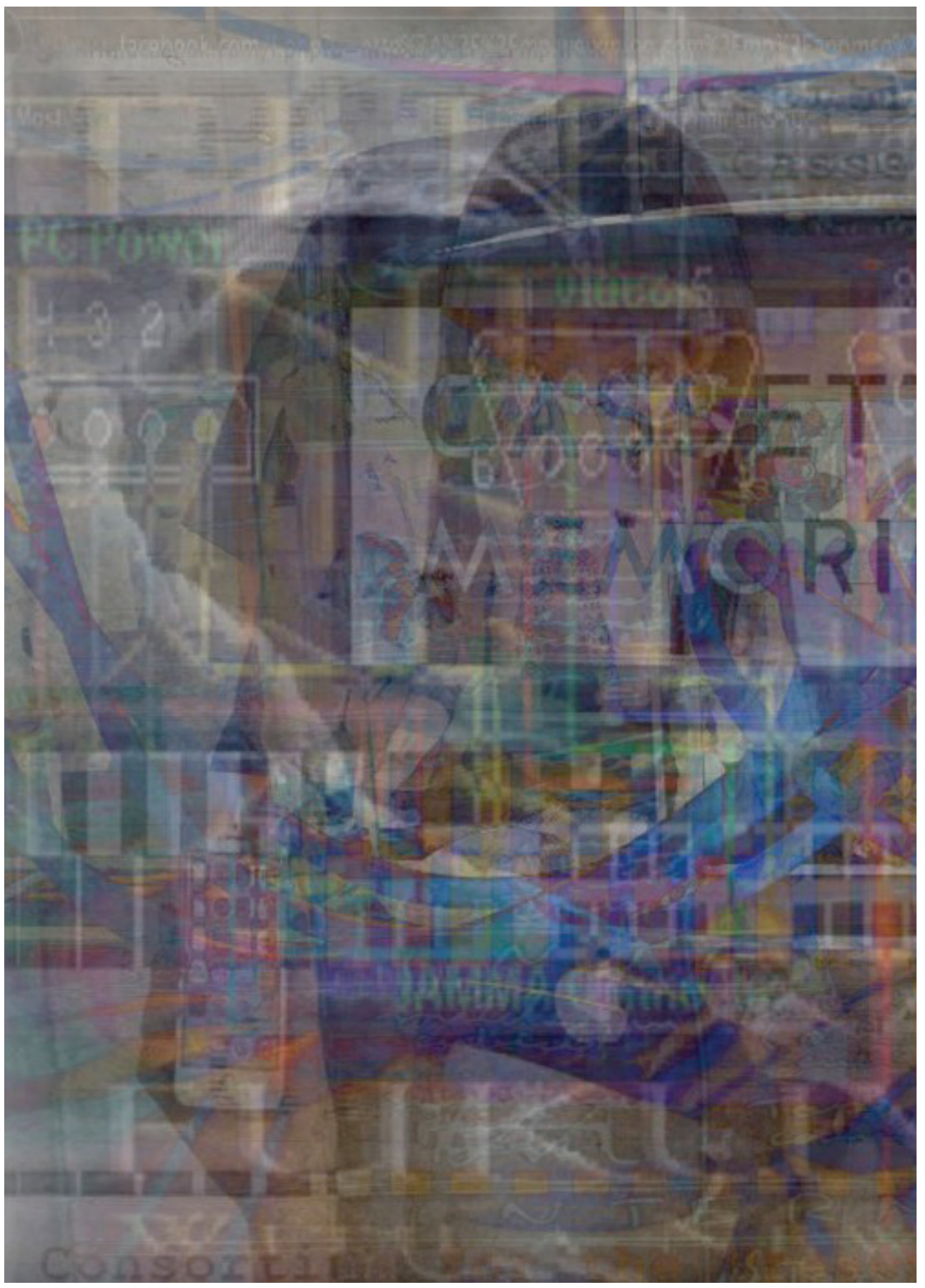




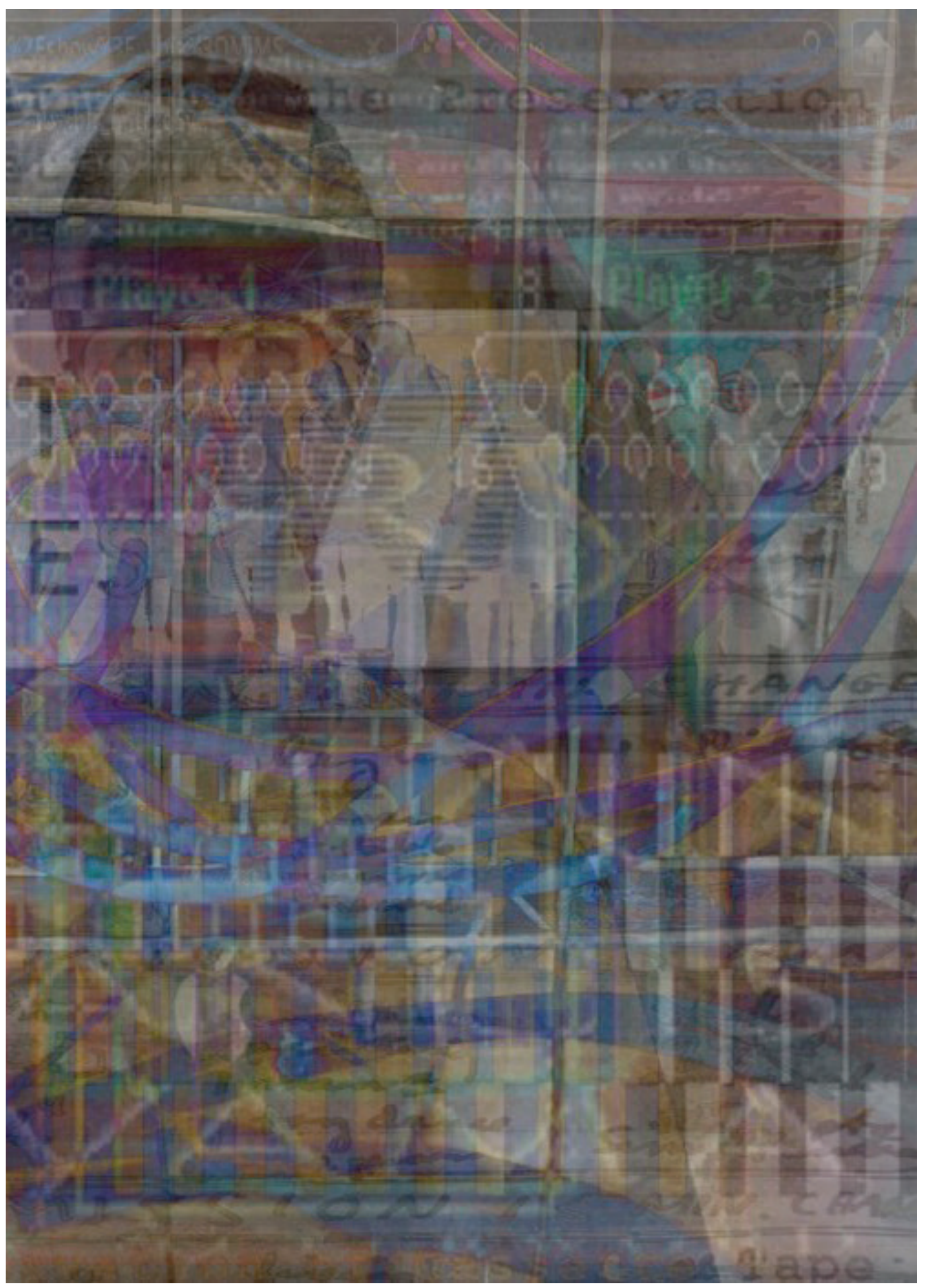

